\title{
Karakteristik Ruang Publik Terpadu Ramah Anak (RPTRA) Bahari di Kecamatan Cilandak Jakarta Selatan
}

\author{
Endy Hernowo dan Ardy Maulidy Navastara \\ Departemen Perencanaan Wilayah dan Kota, Fakultas Teknik Sipil dan Perencanaan, Institut \\ Teknologi Sepuluh Nopember (ITS) \\ e-mail: ardy.navastara@urplan.its.ac.id
}

\begin{abstract}
Abstrak-Kota layak anak menjadi salah satu program strategis dalam Rencana Pembangunan Jangka Menengah Daerah Provinsi DKI Jakarta 2013-2017. Kota Administrasi Jakarta Selatan telah ditetapkan sebagai salah satu wilayah pengembangan kota layak anak oleh Pemerintah Provinsi DKI Jakarta. Salah satu indikator dari Kota Layak Anak adalah tersedianya ruang interaksi publik yang memadai bagi anak. Oleh karena itu, saat ini Pemerintah Provinsi DKI Jakarta telah melakukan perubahan besar yang bisa dilihat dengan konsep baru penyediaan ruang publik yaitu yang bernama Ruang Publik Terpadu Ramah Anak (RPTRA). Artikel ini bertujuan untuk mengidentifikasi karakteristik ruang publik terpadu ramah anak yang sudah terbangun. Dalam artikel ini, RPTRA Bahari di Kecamatan Cilandak menjadi sampel lokasi dikarenakan menjadi pilot project RPTRA di wilayah Jakarta Selatan. Metode yang digunakan dengan analisis deskriptif kualitatif. Artikel ini menunjukkan bahwa ruang publik terpadu ramah anak adalah ruang publik yang memiliki fungsi beragam yang utamanya untuk pendidikan anak dengan mencoba menampilkan konsep yang berbeda dalam pembangunan taman. Ruang publik terpadu ramah anak itu adalah ruang publik yang memiliki karakteristik sebagai taman terbuka publik, wahana permainan dan tumbuh kembang anak, bagian dari prasarana dan sarana kota layak anak, ruang terbuka hijau, dan sarana kegiatan sosial.
\end{abstract}

Kata Kunci-Ruang Publik, Ramah Anak, RPTRA.

\section{PENDAHULUAN}

$\mathrm{T}$ ANTANGAN sekaligus isu kritis di wilayah Provinsi DKI Jakarta salah satunya adalah pemenuhan hak-hak anak. Dalam hukum internasional, terdapat kurang lebih 31 hak anak yang harus terpenuhi dan menjadi urusan wajib bagi negara, agar anak dapat tumbuh dan berkembang menjadi generasi penerus bangsa dalam kebijakan pembangunan berkelanjutan. Sehubungan dengan hal tersebut, pemerintah menggulirkan apa yang disebut dengan Kota Layak Anak (KLA). Perencanaan Kota/Kabupaten Layak Anak (KLA) adalah salah satu upaya pemerintah, masyarakat, dan swasta dalam memenuhi hak-hak anak yang juga merupakan bagian dari komunitas. Sehingga sangat penting untuk direncanakan, mengingat belum ada kota di Indonesia yang sudah benarbenar mencerminkan konsep Kota Layak Anak.[1]

Kota layak anak menjadi salah satu program strategis dalam Rencana Pembangunan Jangka Menengah Daerah Provinsi
DKI Jakarta 2013-2017.[2] Berdasarkan keputusan Menteri Negara Pemberdayaan Perempuan dan Perlindungan Anak Republik Indonesia Nomor 56 Tahun 2010 tentang Penunjukan dan penetapan 10 Provinsi untuk mengembangkan Kabupaten/Kota Layak Anak, Provinsi DKI Jakarta termasuk dalam salah satu provinsi yang ditunjuk untuk mengembangkan Kota Layak Anak bersama dengan 38 Kabupaten/Kota lain di Indonesia.

Kota Administrasi Jakarta Selatan telah ditetapkan sebagai salah satu wilayah pengembangan kota layak anak oleh Pemprov DKI Jakarta melalui Keputusan Gubernur Provinsi DKI Jakarta Nomor 394 Tahun 2011. Salah satu indikator dari Kota Layak Anak adalah tersedianya ruang interaksi publik yang memadai bagi anak.[3] Oleh karena itu, saat ini Pemerintah Provinsi DKI Jakarta telah melakukan perubahan besar dalam hal penyediaan ruang publik yang bisa dilihat dengan pembangunan Ruang Publik Terpadu Ramah Anak (RPTRA), taman multifungsi di wilayah padat penduduk. Pembangunan RPTRA ini dimaksudkan dalam rangka mewujudkan komitmen Pemerintah Provinsi Daerah Khusus Ibukota Jakarta untuk menjamin terpenuhinya hak anak agar anak dapat hidup, tumbuh, berkembang dan berpartisipasi secara optimal sesuai dengan harkat dan martabat dan juga sebagai upaya mendukung DKI Jakarta menjadi Kota Layak Anak.

Oleh karena itu, pengenalan yang lebih mendalam terkait karakteristik ruang publik terpadu ramah anak perlu untuk diteliti karena ini merupakan hal baru dalam konsep penyediaan ruang publik di Indonesia dan pertama kali diterapkan di Provinsi DKI Jakarta. Sehingga nantinya karakteristik RPTRA yang sudah terbangun ini dapat menjadi contoh dan juga pembelajaran bagi kota lain dalam penyediaan ruang dalam perwujudan lingkungan yang ramah anak. Selain itu RPTRA berada di tengah kepadatan pembangunan ibukota, sehingga menjadi lokasi yang tepat untuk dijadikan referensi bagaimana sebuah lingkungan yang memiliki keterbatasan ruang tetap dapat menyediakan ruang kebutuhan anak.[4] Untuk lokasi studi yang menjadi amatan penelitian adalah RPTRA Bahari yang terletak di kelurahan Gandaria Selatan Kecamatan Cilandak. Hal ini dikarenakan didasarkan fakta bahwa RPTRA Bahari ditetapkan oleh Pemprov DKI Jakarta sebagai pilot project atau RPTRA percontohan yang ada di 
wilayah Jakarta Selatan dan sudah mendapatkan penghargaan juara 1 kategori kinerja RPTRA terbaik di wilayah Jakarta Selatan. Sehingga RPTRA Bahari sangat cocok untuk dijadikan sampel lokasi dan dapat merepresentasikan RPTRA di wilayah Jakarta Selatan.

\section{METODE}

\section{A. Variabel}

Variabel yang digunakan untuk mengidentifikasi karakteristik ruang publik terpadu ramah anak (RPTRA) Bahari antara lain kelengkapan fasilitas, keamanan, vegetasi, kenyamanan, keberagaman aktivitas, dan aksesibilitas.

\section{B. Metode Pengumpulan Data}

Metode pengumpulan data yang diguankan dalam penelitian ini adalah dengan teknik survei primer dan survei sekunder. Survei primer dilakukan melalui observasi langsung pada wilayah penelitian yaitu RPTRA Bahari untuk mengetahui gambaran kondisi dan karakteristik ruang publik terpadu ramah anak. Survei sekunder dilakukan dengan survei instansi dan survei literatur. Survei instansi dilakukan pada instansional yang memiliki relevansi dengan pembahasan seperti Dinas Pertamanan dan Pemakaman DKI Jakarta, Badan Pemberdayaan Masyarakat Perempuan dan Keluarga Berencana Provinsi DKI Jakarta, dan Kantor Kecamatan Cilandak. Survei literatur berupa buku, jurnal, dan pedoman pengelolaan ruang publik terpadu ramah anak.

\section{Metode Analisis}

Untuk mengidentifikasi karakteristik ruang publik terpadu ramah anak (RPTRA) Bahari ini digunakan metode analisis deskriptif kualitatif. Analisis ini bertujuan membuat deskripsi secara sistematis, faktual, dan akurat mengenai fakta-fakta suatu wilayah, dalam hal ini yaitu RPTRA Bahari. Analisis bersifat deskriptif dimana data yang terkumpul dalam penelitian ini berbentuk kata-kata atau gambar.[5] Hal ini sesuai dengan tujuan penelitian untuk memperoleh gambaran seutuhnya mengenai suatu objek. Penyajian dengan metode tersebut untuk memberikan gambaran karakteristik masingmasing variabel.

\section{HASIL DAN DISKUSI}

Ruang Publik Terpadu Ramah Anak yang selanjutnya disingkat RPTRA adalah tempat dan/atau ruang terbuka yang memadukan kegiatan dan aktivitas warga dengan mengimplementasikan 10 (sepuluh) program pokok pemberdayaan dan kesejahteraan keluarga untuk mengintegrasikan dengan program Kota Layak Anak. RPTRA berfungsi sebagai taman terbuka publik, wahana permainan dan tumbuh kembang anak, prasarana dan sarana kemitraan antara Pemerintah Daerah dan masyarakat dalam memenuhi kebutuhan hak anak, bagian dari prasarana Kota Layak Anak, ruang terbuka hijau dan tempat penyerapan air tanah, prasarana dan sarana kegiatan sosial warga termasuk pengembangan pengetahuan dan keterampilan kader PKK, usaha peningkatan pendapatan keluarga, pusat informasi dan konsultasi keluarga.
Fokus kegiatan Ruang Publik Terpadu Ramah Anak (RPTRA) mencerminkan layanan bagi anak, layanan masyarakat dan layanan kebencanaan. Ketiga jenis layanan tersebut menjadi kegiatan utama RPTRA yang menjadi wadah "community center".

Ruang Publik Terpadu Ramah Anak (RPTRA) Bahari merupakan salah satu RPTRA yang berada di Kelurahan Gandaria Selatan, Kecamatan Cilandak, Kota Administrasi Jakarta Selatan. RPTRA ini terwujud atas kerjasama Pemprov DKI Jakarta dengan pihak swasta, serta organisasi terkait diantaranya Tanoto Foundation, PT.Unilever Tbk., PT Nestle Indonesia, PT Bintang Toedjoe, PT Indofood Sukses Makmur Devisi Bogasari, Tanoto Foundation.

Pada acara Gebyar Ruang Publik Terpadu Ramah Anak (RPTRA) tahun 2016 yang diselenggarakan oleh Pemprov DKI Jakarta, RPTRA Bahari mendapat penghargaan juara 1 kategori kinerja RPTRA terbaik di wilayah Jakarta Selatan dan juara 3 di lingkup Provinsi DKI Jakarta.

RPTRA Bahari memiliki luas lahan yang kecil, yaitu hanya $926 \mathrm{~m}^{2}$. Hal tersebut membuat RPTRA dibangun sebuah gedung yang memiliki dua lantai untuk tetap dapat mengakomodasi keperluan pelengkap. Luas bangunan lantai satu adalah $98 \mathrm{~m}^{2}$, sedangkan lantai dua memiliki luas $109 \mathrm{~m}^{2}$. Untuk karakteristik kunjungan, menurut pengelola RPTRA kurang lebih terdapat 100 anak yang mengunjungi RPTRA Bahari dalam sehari. Waktu kunjungannya pun bervariasi, mulai dari pagi sampai sore hari namun lebih didominasi pada sore hari yaitu sekitar pukul 15.00-17.30 WIB.

Tabel 1.

Gambaran Umum RPTRA Bahari

\begin{tabular}{l|l}
\hline \hline Alamat & Jl. Bahari Raya RT 09/07 Kec. Cilandak \\
& Jakarta Selatan \\
Lat/Long & -6.278770106 .793513 \\
Luas lahan & $926 \mathrm{~m}^{2}$ \\
Luas bangunan & $98 \mathrm{~m}^{2}($ Lt. 1) \\
& $109 \mathrm{~m}^{2}$ (Lt. 2) \\
Peresmian & 2015 \\
\hline \hline
\end{tabular}

Sumber: Badan Pemberdayaan Masyarakat Perempuan dan Keluarga Berencana Provinsi DKI Jakarta

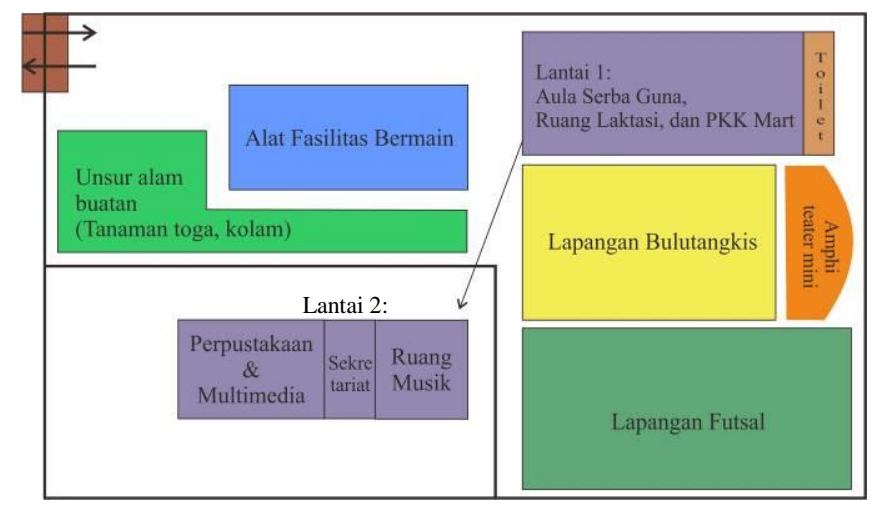

Gambar 1. Layout dari RPTRA Bahari yang didapatkan dari hasil observasi. Sumber: Hernowo \& Navastara, 2017.

Berikut merupakan karakteristik dari RPTRA Bahari berdasarkan masing-masing variabel:

1. Kelengkapan Fasilitas

Fasilitas yang ada di RPTRA Bahari ini terdiri dari fasilitas bermain, fasilitas olahraga, fasilitas bersantai, dan berbagai fasilitas penunjang. Fasilitas bermain yaitu berbagai jenis 
peralatan bermain untuk anak-anak diantaranya adalah perosotan, jungkat jungkit, alat panjat mini, dan ayunan. Semua peralatan memiliki pegangan yang bertekstur halus. Perosotan dan jungkat jungkit terbuat dari material plastik, sedangkan ayunan merupakan metal yang juga memiliki permukaan yang halus. Material lantai dasar di sekitar peralatan bermain adalah pasir tanah. Ketebalannya pun cukup dalam sehingga dapat membantu meredam anak jika terjatuh saat bermain.

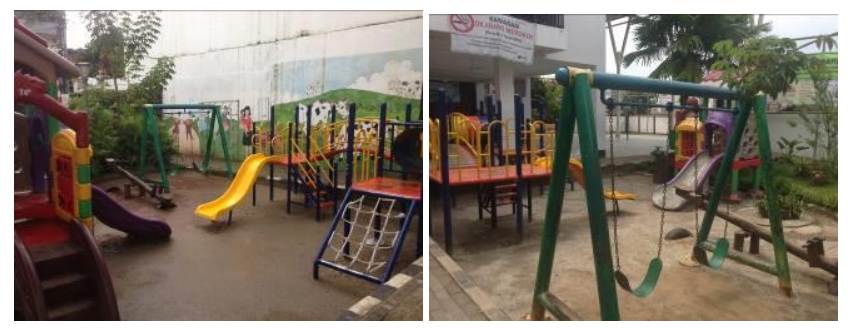

Gambar 2. Fasilitas Bermain di RPTRA Bahari.

Sumber: Hernowo \& Navastara, 2017

Untuk fasilitas olahraga terdapat dua fasilitas olahraga yang disediakan di RPTRA Bahari yaitu lapangan futsal dan lapangan badminton yang letaknya bersebelahan. Sarana olah raga di RPTRA ini menggunakan permukaan yang diperkeras.

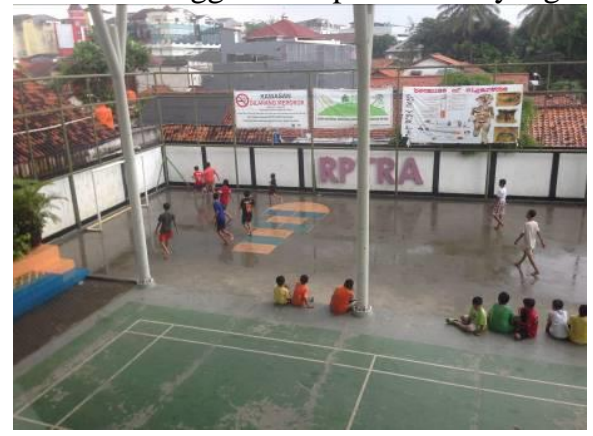

Gambar 3. Fasilitas olahraga berupa lapangan futsal dan badminton. Sumber: Hernowo \& Navastara, 2017.

Untuk fasilitas bersantai terdapat amphi teater mini yang berada di dekat lapangan badminton. Amphi teater ini tidak terlalu besar, dan hanya berupa tempat duduk satu tingkat.

Kemudian berbagai fasilitas penunjang yaitu berupa bangunan dua lantai di RPTRA ini yang di dalamnya terdapat beberapa fasilitas seperti ruang multimedia, perpustakaan, ruang pengurus, PKK Mart, dan aula serbaguna. Toilet dan ruang laktasi juga berada pada bangunan ini.
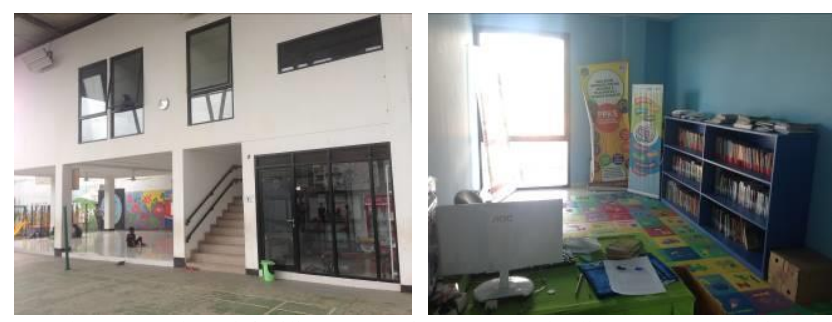

Gambar 4. Berbagai fasilitas penunjang yang ada di RPTRA Bahari. Sumber: Hernowo \& Navastara, 2017.

\section{Keamanan}

RPTRA dikelilingi dengan tembok pada seluruh sisinya. Hal tersebut dikarenakan RPTRA berdekatan langsung dengan rumah warga. RPTRA juga dilengkapi pagar dan kamera CCTV pada pintu masuknya. Untuk menjaga keamanan dan menghindari kriminalitas, maka pada malam hari pagar RPTRA digembok sehingga RPTRA tidak bisa dikunjungi. Juga terdapat pengelola RPTRA berjumlah 5 orang yang bertugas mengawasi anak-anak ketika berada di RPTRA.
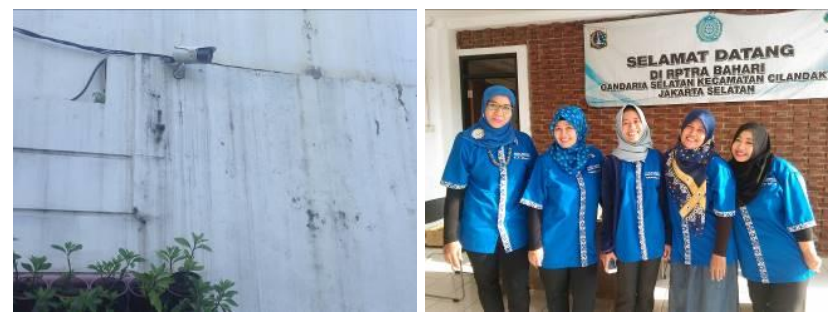

Gambar 5. Kamera CCTV dan para pengelola RPTRA Bahari. Sumber: Hernowo \& Navastara, 2017.

\section{Vegetasi}

Terdapat pepohonan yang merupakan bagian dari Program PKK, yang terdiri dari tanaman hias dan obat-obatan. Pohon dan tanaman penghias yang ada diantaranya Ketapang Kencana tinggi 3-4 m, diameter $8-10 \mathrm{~cm}$ sebanyak 5 pohon, Palem Sadeng tinggi 3-4 m, diameter $8-10 \mathrm{~cm}$ sebanyak 2 pohon, Bougenville tinggi 0,2-0,5 m sebanyak 171 pot, Kemuning tinggi 0,2-0,5 m sebanyak 200 pot dan Puring tinggi $0,5-1 \mathrm{~m}$, sebanyak 288 pot.
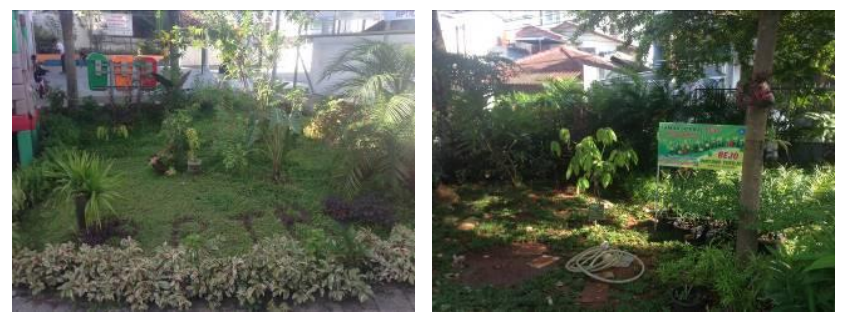

Gambar 6. Berbagai vegetasi yang di RPTRA Bahari.

Sumber: Hernowo \& Navastara, 2017.

\section{Kenyamanan}

Tidak ditemukan bahaya polusi di RPTRA Bahari. Dari segi udara, asap kendaraan tidak memiliki dampak besar, karena kepadatan kendaraan yang sangat kecil di lokasi tersebut. Sedangkan untuk asap rokok, terdapat larangan merokok di dalam RPTRA. Selain itu juga terdapat beberapa aturan dan larangan agar pengguna merasa nyaman ketika berada RPTRA yang dipajang di salah satu tembok. Terdapat pepohonan untuk melindungi dari sinar matahari juga atap pelindung yang berfungsi untuk melindungi dari hujan juga bisa melindungi RPTRA dari panas matahari.

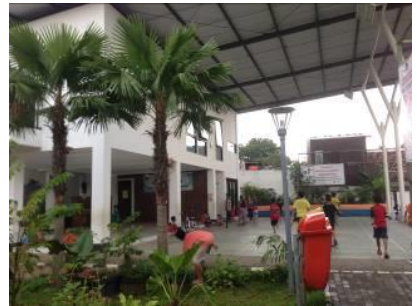

Gambar 7. Atap pelindung RPTRA Bahari.

Sumber: Hernowo \& Navastara, 2017.

\section{Keberagaman Aktivitas}

Terdapat berbagai macam kegiatan aktivitas yang diadakan di RPTRA Bahari ini. Diantaranya yaitu latihan menggambar, 
latihan tarian tradisional, bimbingan belajar, pelatihan futsal, forum belajar anak, dan senam aerobik. Kegiatan atau aktivitas sudah terjadwal setiap harinya. Aktivitas atau program ini bisa diusulkan oleh pengelola RPTRA dan masyarakat sekitar. Adanya kegiatan di dalam RPTRA tersebut akan membuat orang berkeinginan untuk datang kembali. Apabila tidak ada kegiatan yang dapat dilakukan di dalam ruang publik tersebut, ruang akan menjadi ksong dan akhirnya ruang tersebut mati.
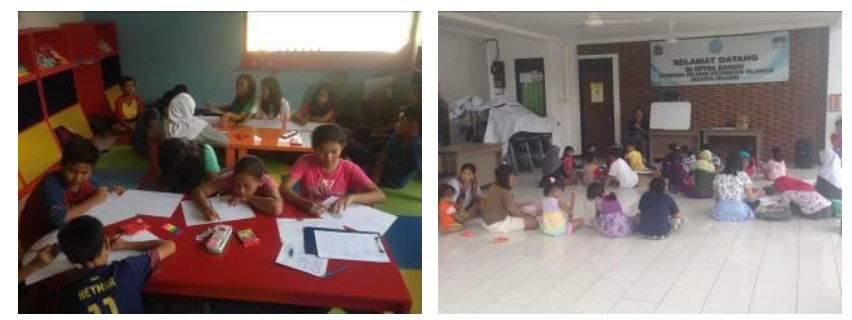

Gambar 8. Ragam aktivitas yang dilakukan di RPTRA Bahari.

Sumber: Hernowo \& Navastara, 2017.

\section{Aksesibilitas}

Di dalam aksesibilitas, terdapat kriteria kualitatif berupa terasa dekat, memiliki keterkaitan dengan ruang lain, nyaman bagi pejalan kaki, dan akses yang mudah. Dilihat dari guna lahan sekitar, RPTRA Bahari berada di tengah-tengah kawasan perumahan warga dengan lingkungan perkampungan cukup padat. Hal ini membuat anak-anak sekitar merasa dekat dan cukup mudah untuk menuju ke RPTRA. Semua ruas jalan merupakan jalan dengan skala pelayanan jalan lingkungan, yang menghubungkan antar rumah warga. Ruas jalan masih dapat dilalui oleh dua lajur mobil bersamaan. Kualitas badan jalan di kawasan tersebut dapat dikatakan baik yaitu tidak terdapat jalan yang rusak atau berlubang. Namun, tidak ada daerah khusus pejalan kaki atau pesepeda dan tidak ditemukan zona penyebrangan pada seluruh ruas jalan akses menuju RPTRA Bahari untuk mengakomodasi pejalan kaki dan pesepeda, khususnya anak-anak.

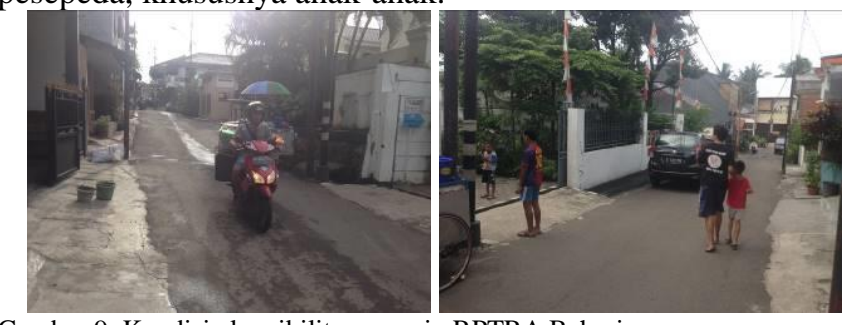

[3]

[4]

\section{KESIMPULAN}

Berdasarkan hasil analisis dan pembahasan, maka dapat disimpulkan bahwa yang dimaksud dengan ruang publik terpadu ramah anak adalah ruang publik yang berfungsi sebagai taman terbuka publik, wahana permainan dan tumbuh kembang anak, bagian dari prasarana dan sarana kota layak anak, ruang terbuka hijau, dan sarana kegiatan sosial. Berikut ini karakteristik RPTRA Bahari di Kecamatan Cilandak Jakarta Selatan:

1. Terdapat berbagai macam fasilitas yang disediakan yaitu fasilitas bermain, fasilitas olahraga, fasilitas bersantai, dan berbagai fasilitas penunjang.

2. Dari segi keamanan RPTRA dilengkapi pagar dan kamera CCTV pada pintu masuknya. Juga terdapat pengelola RPTRA yang bertugas mengawasi anak-anak ketika berada di RPTRA.

3. Terdapat pepohonan yang merupakan bagian dari Program PKK, yang terdiri dari tanaman hias dan obat-obatan.

4. Untuk kenyamanan, RPTRA merupakan area bebas asap rokok dan terdapat pepohonan untuk melindungi pengunjung dari sinar matahari.

5. Terdapat berbagai macam kegiatan aktivitas yang diadakan di RPTRA Bahari yang sudah terjadwal setiap harinya.

6. Dari segi aksesibilitas, RPTRA Bahari berada di tengahtengah kawasan perumahan warga sehingga membuat anakanak sekitar merasa dekat dan cukup mudah untuk menuju ke RPTRA.

\section{DAFTAR PUSTAKA}

[1] Badan Pemberdayaan Masyarakat Perempuan dan Keluarga Berencana Provinsi DKI Jakarta, Pedoman Pengelolaan Ruang Publik Terpadu Ramah Anak. Jakarta: Badan Pemberdayaan Masyarakat Perempuan dan Keluarga Berencana Provinsi DKI Jakarta, 2015.

RPJMD DKI Jakarta 2013-2017.

Media Jaya Nomor 05 Tahun 2015. 2015.

D. Sabila, F., \& Zulkaidi, "Evaluasi Kinerja Ruang Publik Terpadu Ramah Anak Sungai Bambu Jakarta Utara," J. Perencanan Wil. dan Kota 1 SAPPK, pp. 1-10, 2015.

B. Bungin, Analisis Data Penelitian Kualitatif. Jakarta: PT. Rajagrafindo Persada, 2010.

Gambar 9. Kondisi aksesibilitas menuju RPTRA Bahari.

Sumber: Hernowo \& Navastara, 2017. 